\title{
Pursuing a Better Elementary Japanese Textbook for Indonesian Learners
}

\author{
Agus Suherman Suryadimulya ${ }^{1, *} \&$ Tadashi Sakamoto ${ }^{2}$ \\ ${ }^{1}$ Padjadjaran University, Bandung, Indonesia \\ ${ }^{2}$ Nanzan University, Nagoya, Japan \\ *Corresponding author: Padjadjaran University, Bandung, Indonesia. E-mail: \\ toez17@gmail.com
}

Received: January 24, 2014 Accepted: March 3, 2014 Published: March 26, 2014

doi:10.5296/ije.v6i1.5363ＵRL: http://dx.doi.org/10.5296/ije.v6i1.5363

\begin{abstract}
Japanese language textbooks used in many universities and schools in Indonesia these days are not designed to be used by the Indonesian learners. In this paper, we conducted a survey on 151 Indonesian leaners who are currently studying Japanese in universities in Indonesia. We applied quantitative and qualitative methods to collect data and employed five point scale questionnaires and an open-ended question to understand the characteristics of the textbook that the learners want/need.

The questionnaires contained sixty seven questions which were evaluated on a five point scale from 'strongly agree' to 'strongly disagree' by the subjects. The main findings were that the learners wish to (1) learn all four skills, and want to improve their speaking skill the most; (2) learn grammar rules through many example sentences, (3) acquire knowledge from contrastive analysis between Indonesian and Japanese in the areas of language, culture, customs, and manners; (4) learn standard language and also major dialects, language of the young, children, aged people, words of foreign origin, onomatopoeia, body language, and honorific language; (5) practice meaningful drills, discourse, role-play, shadowing, translation, and composition; (6) expose themselves to Kanji from the beginning; (7) have bidirectional vocabulary list of Japanese and Indonesian.

Based on this survey, we concluded that Indonesian learners of Japanese are looking forward to the emergence of newly written innovative Japanese language textbooks that fit the expectancies of the Indonesian learners and also make the full use of the outcome of contrastive study of language and culture.
\end{abstract}

Keywords: Indonesian; textbook; questionnaires; quantitative; qualitative; contrastive 


\section{Introduction}

It has been said by many Japanese language professionals that Japanese language textbooks currently used in many universities and schools in Indonesia are not written in a form that is suitable for Indonesian learners, but written for any learners of Japanese. Textbooks writers should make full use of accumulated knowledge and skills obtained from accomplishments of the contrastive analysis of languages and cultures from the last century, and Japanese language textbooks currently used in Indonesia should have taken advantage of these accomplishments.

Now, it is time for a new textbook to be written in order to make use of accomplishment made in the contrastive analysis between Indonesian and Japanese in both language and culture, for the sake of future Indonesian learners of Japanese. It is very regrettable that we could not find any articles and books so far that make reference to elementary Japanese textbooks for Indonesian learners.

Our purpose in this article is to identify what kind of textbook is expected to be written for the Indonesian learners of Japanese who are currently studying Japanese and culture in Indonesia.

We hope that this study will stimulate future Japanese textbook publications for the country that had more than 710,000 Japanese learners in 2009 according to Japan Foundation survey in 2011. Now the number of Japanese learners in Indonesia is in the third place among the countries in the world, following Korea and China, and Indonesia had the top learner population growth rate of over $160 \%$ in 2009.

\section{Research Questions}

There are three research questions in this article.

1) To quantitatively extract the elements of the desirable textbook by doing a five-point scale questionnaire to the Indonesian learners of Japanese.

2) To qualitatively extract the elements of the desirable textbook by doing a five-point scale questionnaire to the Indonesian learners of Japanese.

3) To propose an outline of an ideal textbook for the Indonesian learners of Japanese.

\section{Methodology}

Subjects: 151 Indonesian learners of Japanese studying in Bandung. There were 41 male students and 114 female students; 22 in the third semester, 125 in the fifth semester, and 4 in the seventh semester, respectively.

Data Collection: We asked the learners of Japanese to check the most suitable answer for sixty seven five-point scale questionnaires from "strongly agree" to "strongly disagree," and to write a description about the Japanese textbook they desire.

\section{5: strongly agree}


4: agree

3: does not matter

2: disagree

1: strongly disagree

Questionnaires: The following are the questions:

Q1: I want to acquire all four language skills - reading, writing, speaking, and listening in a balanced manner.

Q2: I first want to acquire conversational skills of speaking and listening.

Q3: I first want to acquire reading and writing skills.

Q4: As for grammar rules, I prefer to elicit them from example sentences.

Q5: As for grammar rules, I hope that they will be introduced as rules.

Q6: As for grammar explanations, the introduction of basic rules is enough.

Q7: As for grammar explanations, I want detailed explanations.

Q8: I do not require explanations contrasting Japanese and Indonesian.

Q9: I learn better when receiving explanations contrasting Japanese and Indonesian.

Q10: It is better to have columns explaining Japanese culture, customs, and manners in Indonesian.

Q11: It is better to have columns contrasting Japanese and Indonesian's culture, customs, and manners in Indonesian.

Q12: I want to learn standard Japanese.

Q13: I want to learn not only the standard Japanese but also strong dialects.

Q14: I also want to learn children’s Japanese.

Q15: I also want to learn children’s Japanese and also elderly people’s Japanese.

Q16: I want to learn frequently-used words adopted from foreign languages.

Q17: I want to learn frequently-used onomatopoeic expressions.

Q18: It is better to have the dialogues with plot.

Q19: I want to read the dialogues both in formal and informal style.

Q20: I want to learn Japanese honorific language.

Q21: It is better to have pictures and illustrations.

Q22: It is better to have audio learning materials.

Q23: It is better to have information on nonverbal aspects of speech such as Japanese 
gestures.

Q24: It is better to have signs such as streets and factories.

Q25: It is better to have animation, comic strip.

Q26: It is better to have pronunciation practices every lesson.

Q27: It is better to have mechanical drills such as forming a Japanese sentence in a mechanical manner.

Q28: It is better to have meaningful drills such as forming Japanese sentences and understanding the context and what people are saying.

Q29: It is better to have exercises to create sentences and discourses in Japanese.

Q30: It is better to have task-type exercises in Japanese.

Q31: It is better to have role-play exercises in Japanese.

Q32: It is better to have discussion and debate in Japanese.

Q33: It is better to have shadowing exercises.

Q34: It is better to have translation exercises from Indonesian to Japanese.

Q35: It is better to have writing exercises not only making a sentence but also making a discourse.

Q36: It is better to have a reading every lesson.

Q37: It is better to have a section on new words and phrases in readings.

Q38: I want to learn Japanese society and customs through reading materials.

Q39: I want to read the old folk tales of Japan that are popular among the Japanese.

Q40: I want to read Japanese comical stories.

Q41: It should have a section to practice intensive reading, speed reading, skimming and scanning.

Q42: Word list should include Japanese to Indonesian translation.

Q43: Word list should also include Indonesian to Japanese translation.

Q44: It is better to have all Japanese words in the aiueo order at the end of the textbook.

Q45: All words in the lessons should be listed at-the end of the textbook.

Q46: It is better to have particle information associated with each Japanese verb when it is introduced for the first time.

Q47: It is better to have example sentences using new words and phrases at the end of the textbook. 
Q48: It is better to have antonym information.

Q49: It is better to have Japanese pronunciation practices every lesson.

Q50: It is better to have Japanese accent practices every lesson.

Q51: It is better to have Japanese rhythm practices every lesson.

Q52: It is better to have Japanese intonation practices every lesson.

Q53: It is better to have Japanese riddles and games on words.

Q54: I want to distinguish between words for comprehension and words for use, and learn them both.

Q55: I want to learn Kanji (Chinese character) little by little.

Q56: Kanji (Chinese character) can be introduced from the first class for passive learning as long as it is shown with its readings.

Q57: I do not need to be able to write Kanji (Chinese character) correctly as long as I can read them.

Q58: I want to study Japanese using authentic materials even if they are difficult to read.

Q59: I want to do exercises that enhance my level of critical thinking.

Q60: It is better to have a quiz for review purposes in every lesson.

Q61: It is better to have review exercises every four or five lessons.

Q62: It is better to have pair work and group work every lesson.

Q63: It is better to have error correction exercises.

Q64: It is better to have communication gap information between the Japanese and Indonesian.

Q65: I do not need CD materials.

Q66: I mainly want to learn how to read Kanji (Chinese character) rather than writing them.

Q67: I want to learn how to read and write Kanji.

A question of free description about their desired Japanese textbook is as follows:

Q: In the following space, please write the descriptions

of your ideal Japanese language textbook. 


\section{Macrothink}

International Journal of Education

ISSN 1948-5476

2014, Vol. 6, No. 1

\section{Results and Discussion}

We would like to present the results of this survey according to the topics of the questions.

four skills: questions 1 - 3

grammar: questions $4-7$

contrast: questions $8-11$

dialogues: questions $12-20$

audio-visual aids: questions $21-25$

drills and exercises: questions $26-35$

reading materials: questions $36-41$

words and phrases: questions $42-48$

pronunciation: questions $49-52$

others: questions $53-67$

\subsection{Four Skills}

Figure 1 indicates the results of four skills that the subjects want to learn. The figure illustrates that more learners want to acquire speaking and listening skillsi more than reading and writing skills. It is very understandable that learners first want to improve oral communication skills which enable them to converse with Japanese speakers in Japanese.

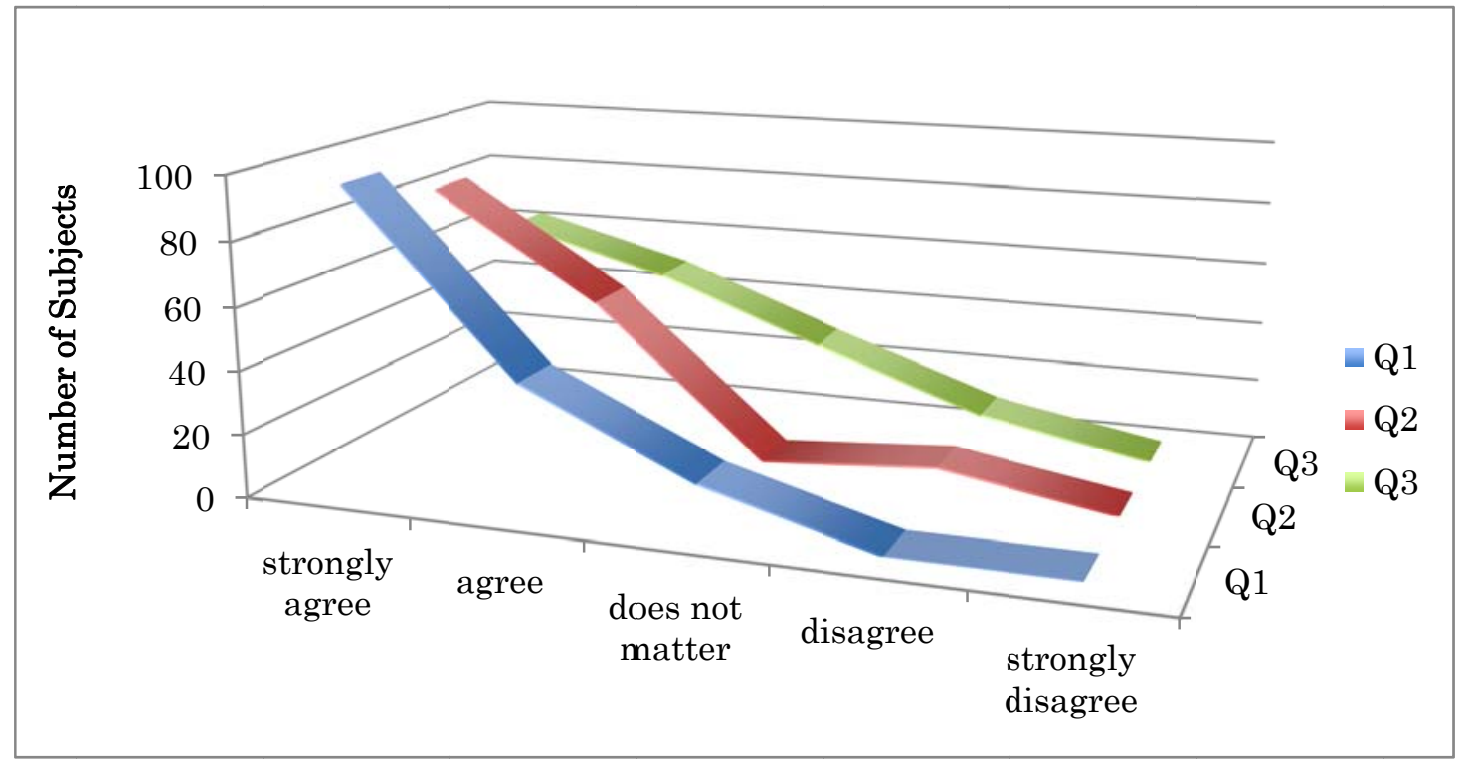

Figure 1. Four Skills 


\subsection{Grammar}

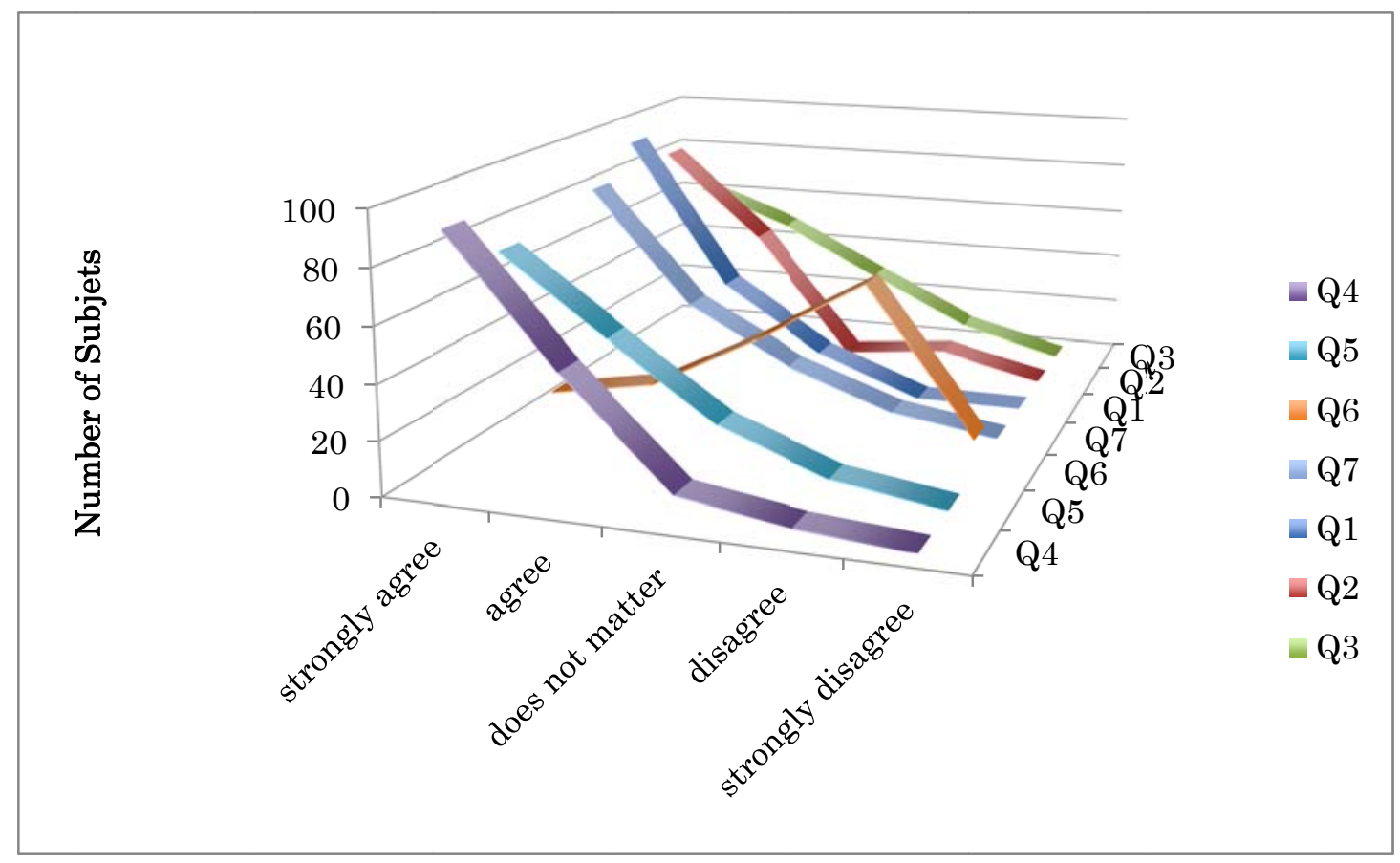

Figure 2. Grammar

From Figure 2, we learned that there are more learners who want to learn grammar through extracting from example sentences than being passively provided with grammatical points. This does not appear to be in agreement with most language teachers' belief that grammar should be taught explicitly in words. Many of the existing Japanese textbooks' grammar introductions do not follow the learners wish mentioned above.

Furthermore, learners do not expect detailed descriptions of grammatical points but only the fundamental basic descriptions of them, which falls in line with one of the arguments that second language acquisition research has claimed.

\subsection{Contrast}

Figure 3 shows the survey results of contrast such as language, culture, custom, and manners. Subjects in this study want to have explanations contrasting two languagesi, cultures, customs, and manners. It is not realistic to give those explanations in Japanese in an elementary level textbook, but it is reasonable to give those explanations in their native language. Learners of Japanese will have opportunities to study similarities and differences between these two languages and countries in their early stage of learning which is very beneficial for learners and also motivate them to become interested in the contrastive viewpoints. 


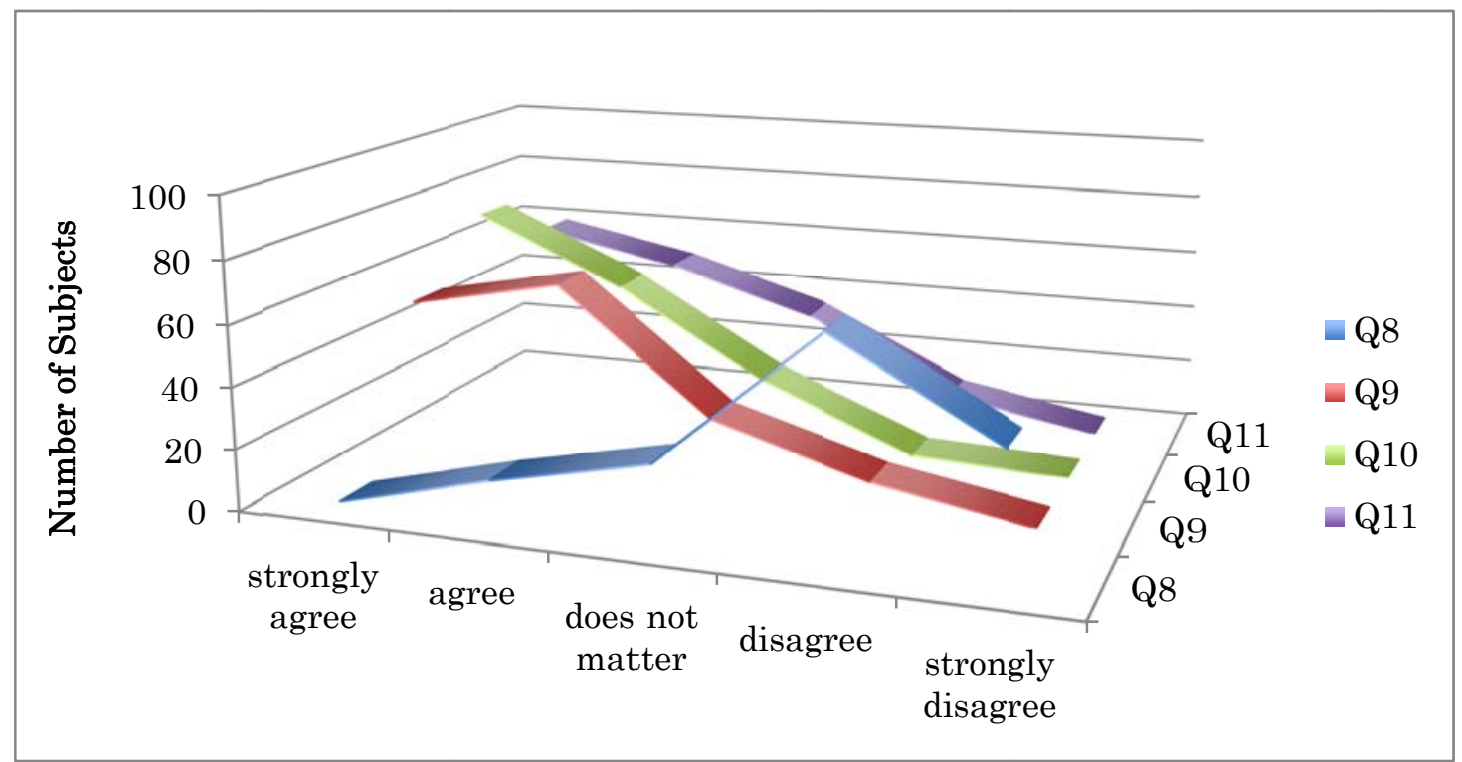

Figure 3. Contrast

\subsection{Dialogues}

Figure 4 clearly illustrates that the subjects want to study the standard Japanese, but at the same time, learn its language in order to communicate with Japanese of all ages: strong dialects, young people’s Japanese, children's Japanese, elderly people’s Japanese, loan words (words adopted from foreign languages), frequently-used onomatopoeic expressions, formal and informal styles, and Japanese honorific language. It is particularly worth noting that almost all of the subjects prefer to learn Japanese honorific language (Keigo) and formal and informal styles of Japanese. This preference may have resulted from their motivation for acquiring the Japanese for business purposes.

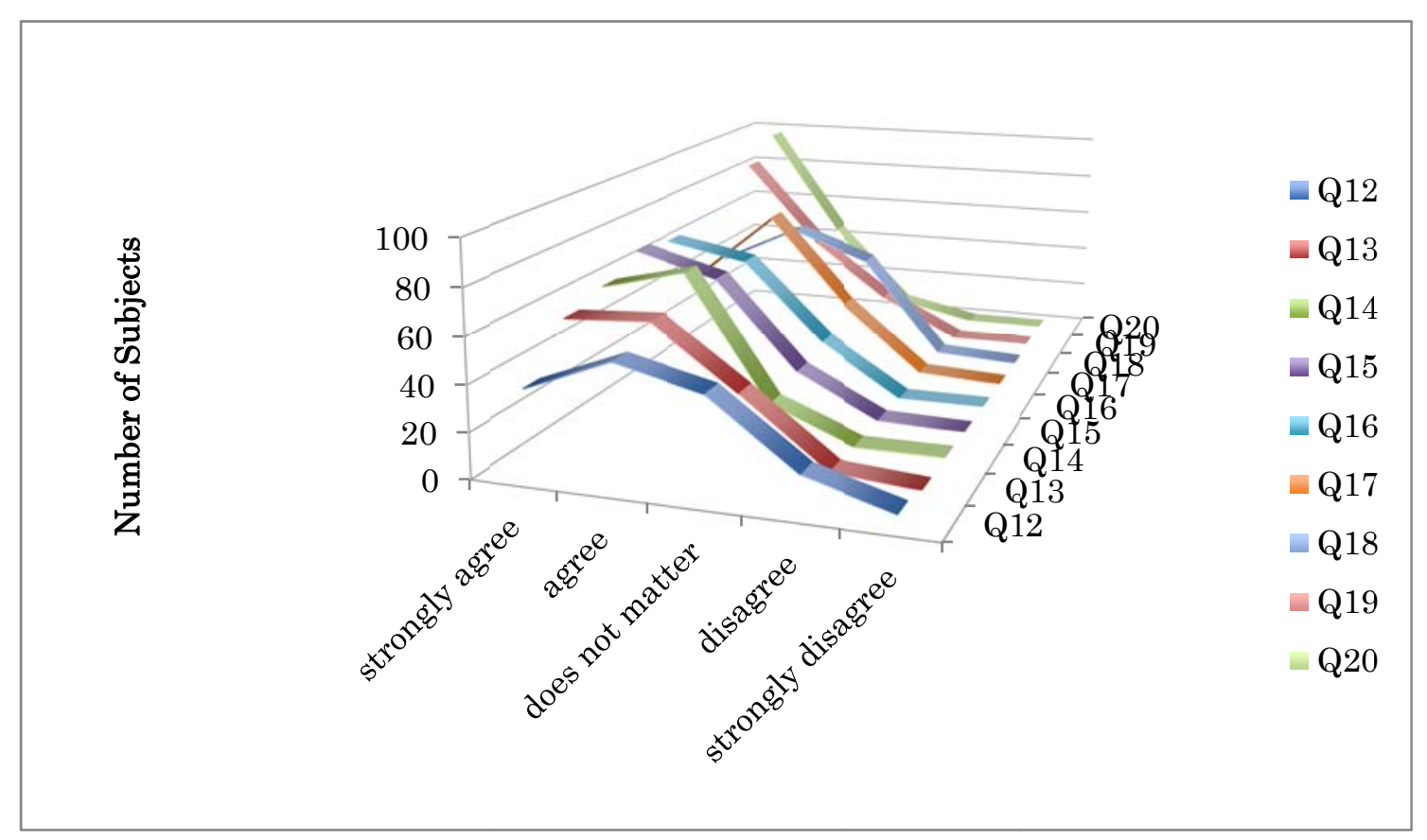

Figure 4. Dialogues 


\subsection{Audio-visual Aids}

It is very difficult to find Japanese language textbooks that do not have any audio-visual aids such as pictures, illustrations, cartoons, signs, tapes, CDs, and DVDs these days. Without the audio-visual aids learners are going to face difficulties to keep their motivation to learn the language just by reading textbooks full of characters. The use of audio-visual aids will help learners memorize new words and phrases of the language, and on top of this, it will let them appreciate the learning processes which also help them to maintain their motivations for a long period of time. Figure 5 expresses this that subjects prefer to use audio-visual aids when learning Japanese.

Preparing audio-visual aids is not an easy job and in fact, finding professional radio actors appropriate for the characters in the dialogues of the textbook is difficult. However, it is still important to prepare audio-visual aids that will help learners to learn the language in an enjoyable manner.

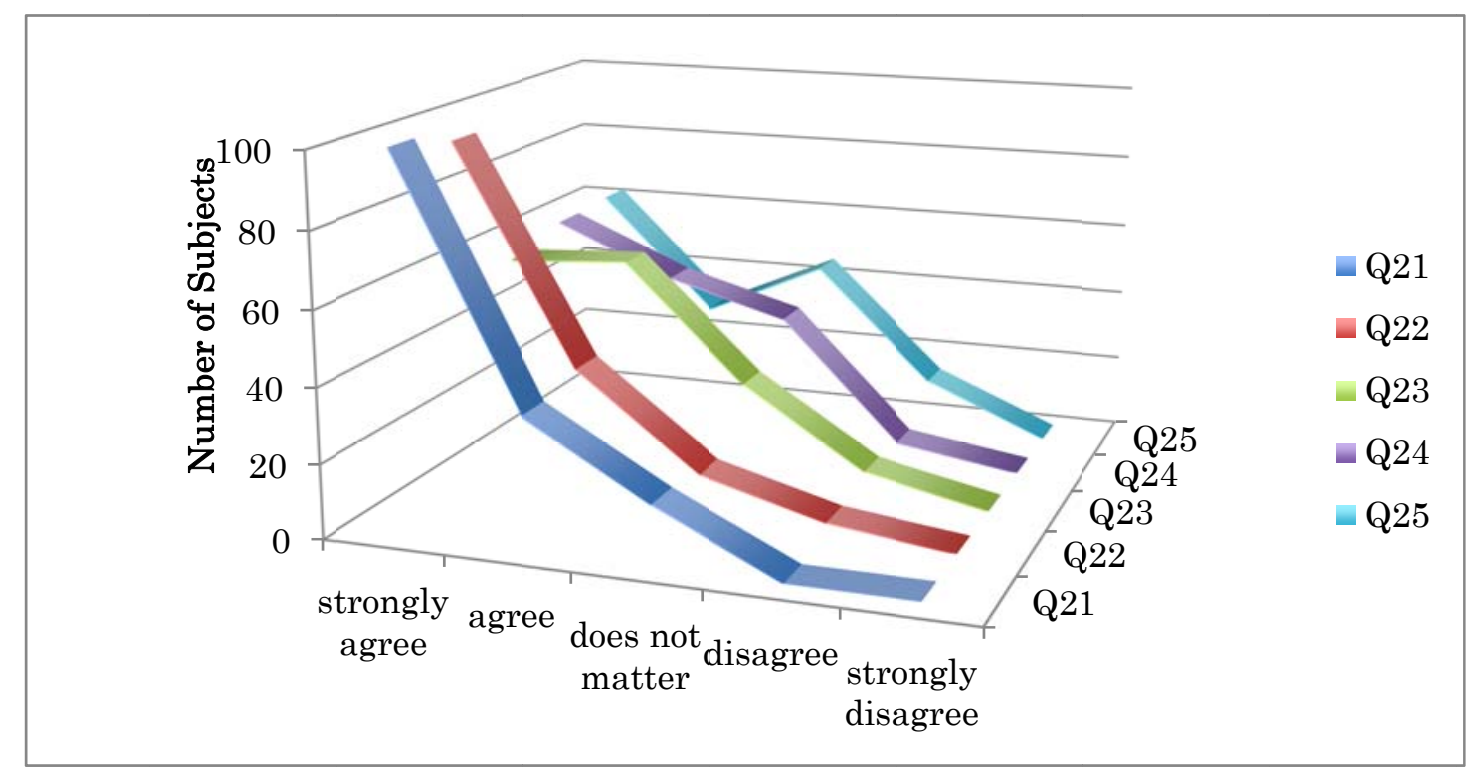

Figure 5. Audio-Visual Aids

\subsection{Drills and Exercises}

In drill and exercise sections, almost all of the existing Japanese language textbooks contain a large number of drills and exercises. However, after taking a close look at them, it will take no time to be aware of the fact that those drills and exercises are very mechanical. That is, learners can perform the task, in the worst case, without understanding the meaning of what they are saying. However, it is somehow surprising that learners in this research find some value on those mechanical drills. This may reflect a possibility that learners worry about accuracy of their performance since accuracy of the language is most easily picked up by the language teachers in the classroom and becomes a target of error correction and feedback. It is understandable that both teachers and learners are more inclinable to be conscious about accuracy of the language produced by learners.

Figure 6 show that the subjects moderately prefer to receive various kindls of exercises such 
as mechanical drills, meaningful drills, discourse exercises, task-type exercises, role-play exercises, shadowing exercises, translation exercises, writing exercises, and discussion and debate in Japanese. Textbook writers should try to make various types of exercises that can keep learners to actively get involved in language learning.

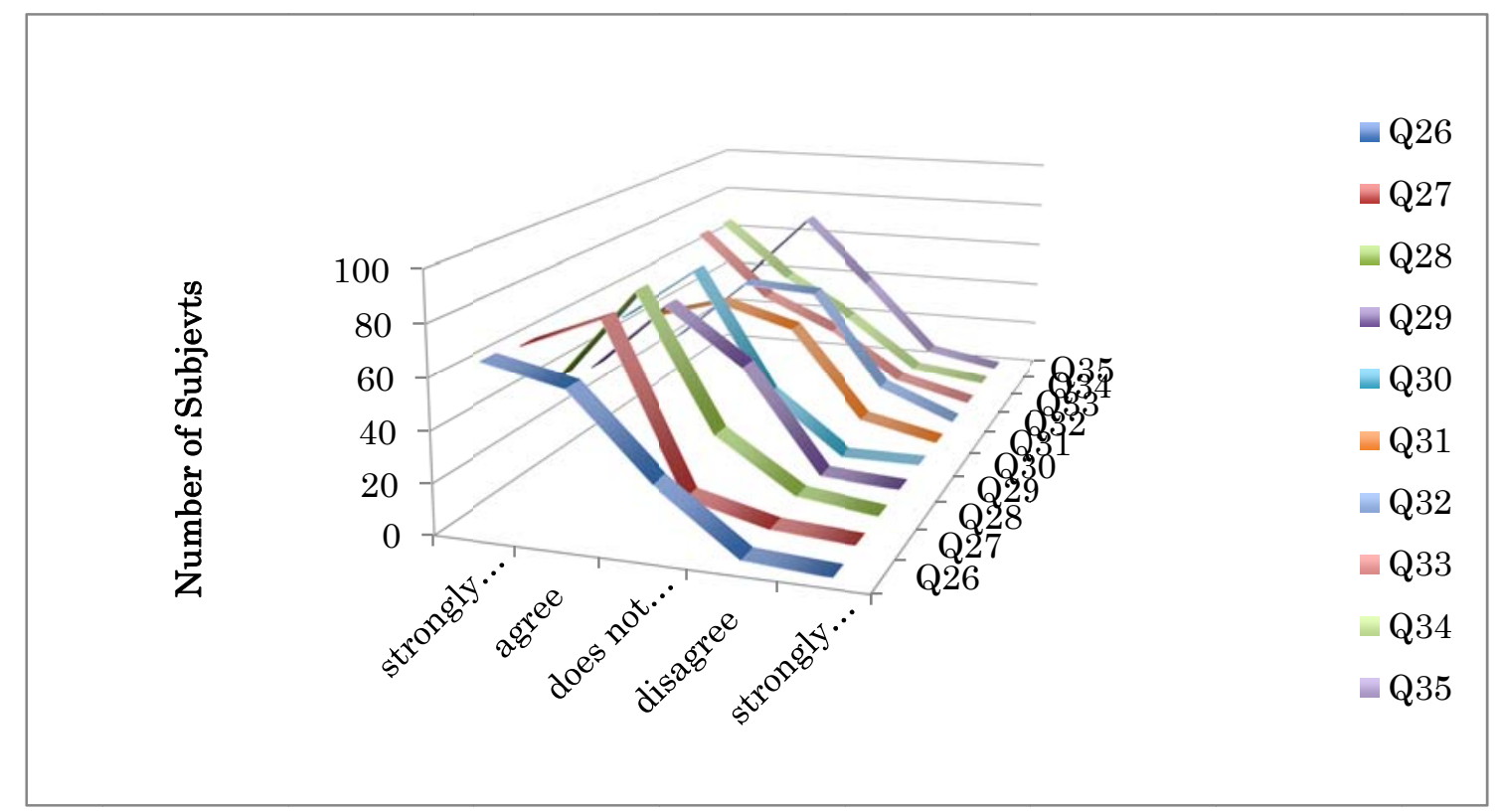

Figure 6. Drills and Exercises

\subsection{Reading Materials}

Reading is one of the important skills to acquire, but it is a rather difficult skill to develop. Learners are not usually interested in reading materials which are aimed just to learn new grammar and new vocabulary, but are more interested in reading materials that contain information of society, culture (traditional culture, sub culture, and pop culture), customs, history, and current affairs of the target country. Reading materials should include these contents. The result of our questionnaires reflects this point (Figure 7) and let us further inform that subjects want to read old folk tales of Japan and Japanese comical stories. It also turned out that subjects wish textbooks to include not only intensive reading, but also speed reading, skimming and scanning practices.

Another interesting point is that most textbook writers have a tendency to restrict the number of new vocabulary in each lesson to reduce the burden of learners to learn new vocabulary. They hesitate to introduce new vocabulary especially in other sections. Usually, new words and phrases are introduced in the section of dialogues, and are rarely introduced in reading sections, and drill and exercise sections. However, this research have reveled that subjects are not reluctant at all to learn new vocabulary in sections other than the dialogue sections. It seems that subjects do not mind learning new words and phrases anywhere in the textbooks. 


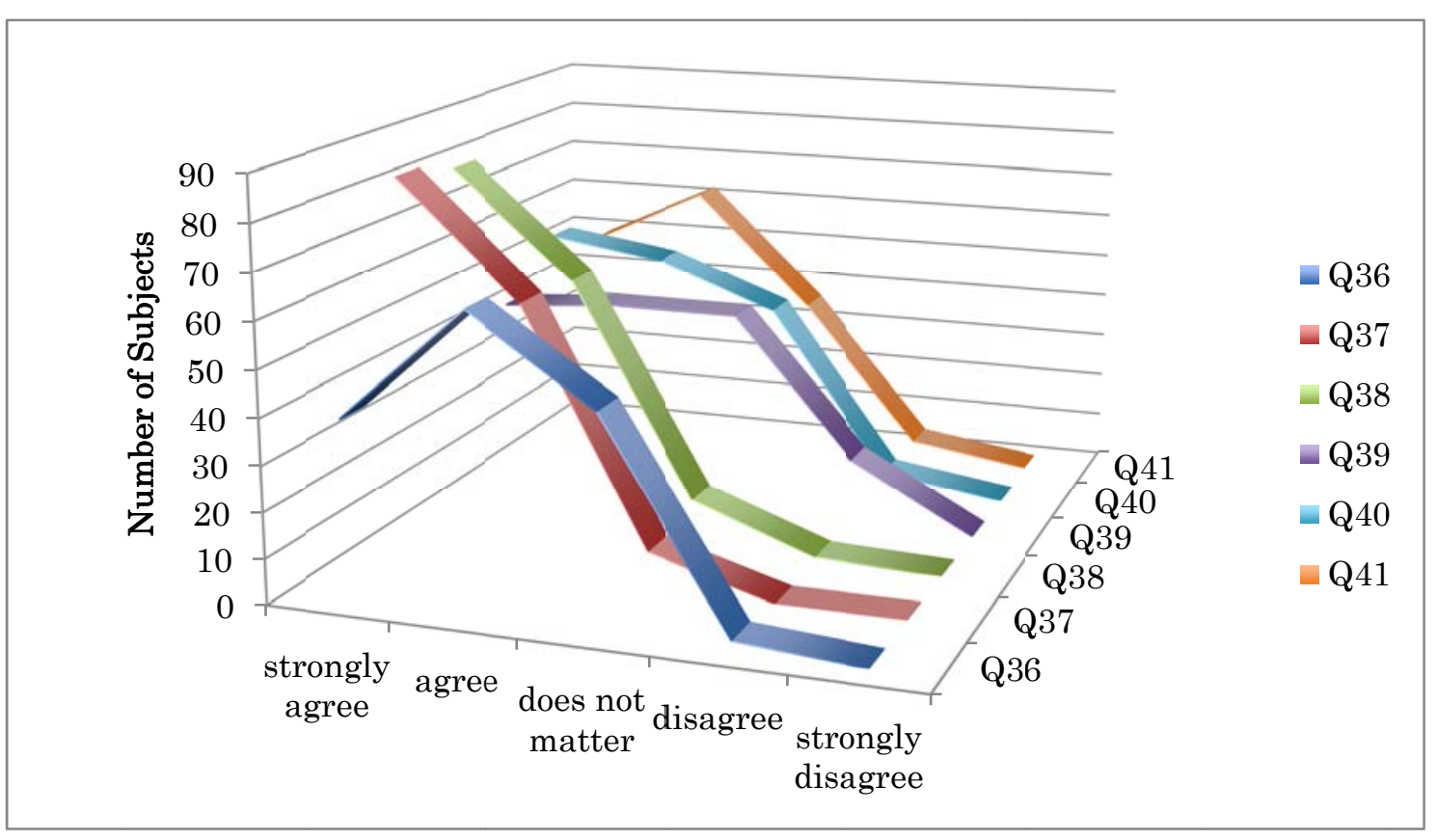

Figure 7. Reading Materials

\subsection{Words and Phrases}

Most language textbooks have word list for each lesson and a glossary of all the new words and phrases introduced at the end of the book. However, it is more often the case that this glossary is one-way list, that is, glossary of the target foreign language to the learner's native language. Language textbooks, especially textbook of the elementary level, are used as a dictionary since many students in an elementary class do not usually have a dictionary. Our research also indicates this point from Figure 8 that the subject wish to have two way glossaries, and furthermore particle information associated with each Japanese verb, example sentences using new words and phrases, and antonym information in the textbook. This shows the learners' attitude towards how they want to learn the target language. Textbook writers should gain a better understanding of the fact that learners want to acquire communication and performance knowledge, and not passive, static knowledge of grammar and words and phrases. 


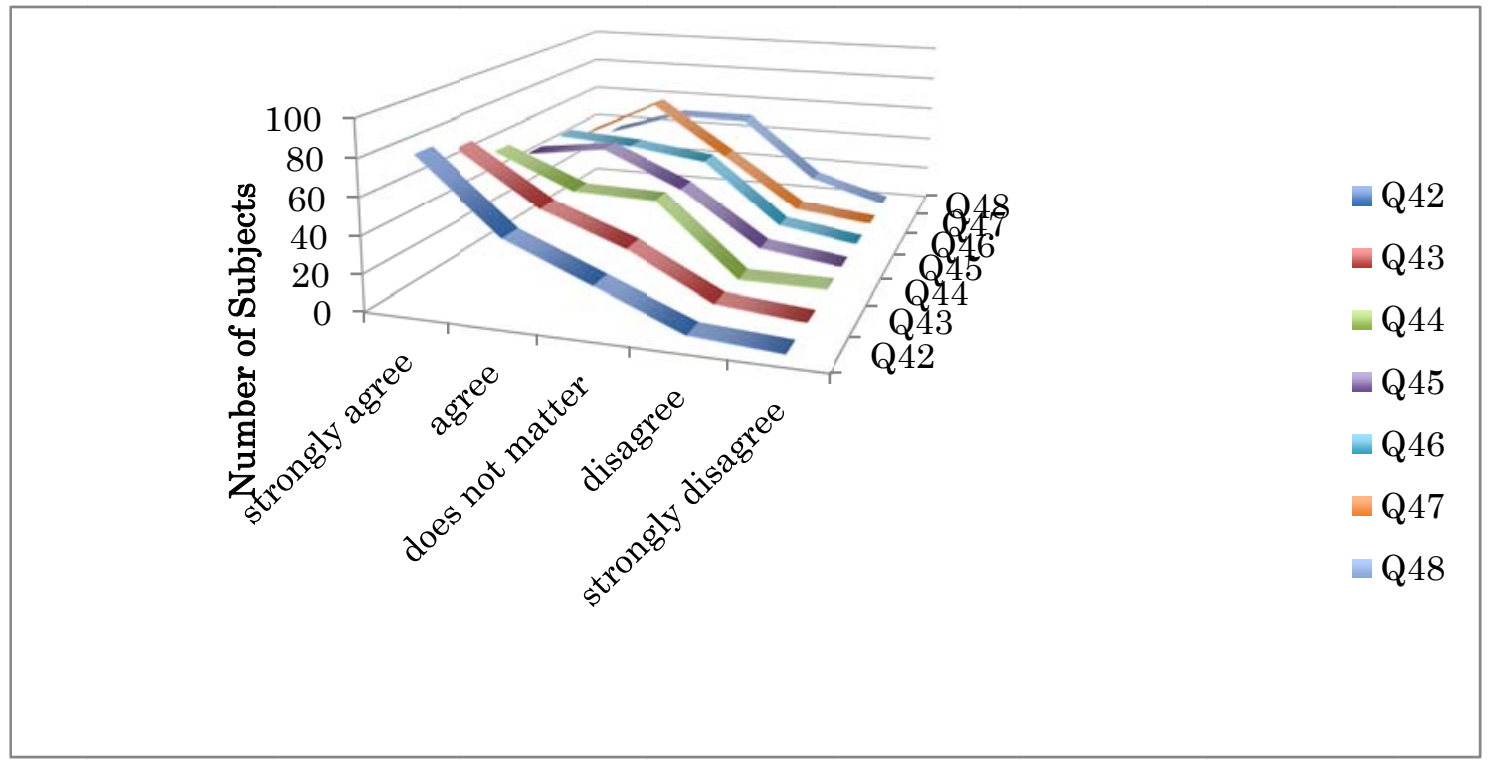

Figure 8. Woords and Phrases

\subsection{Pronunciation}

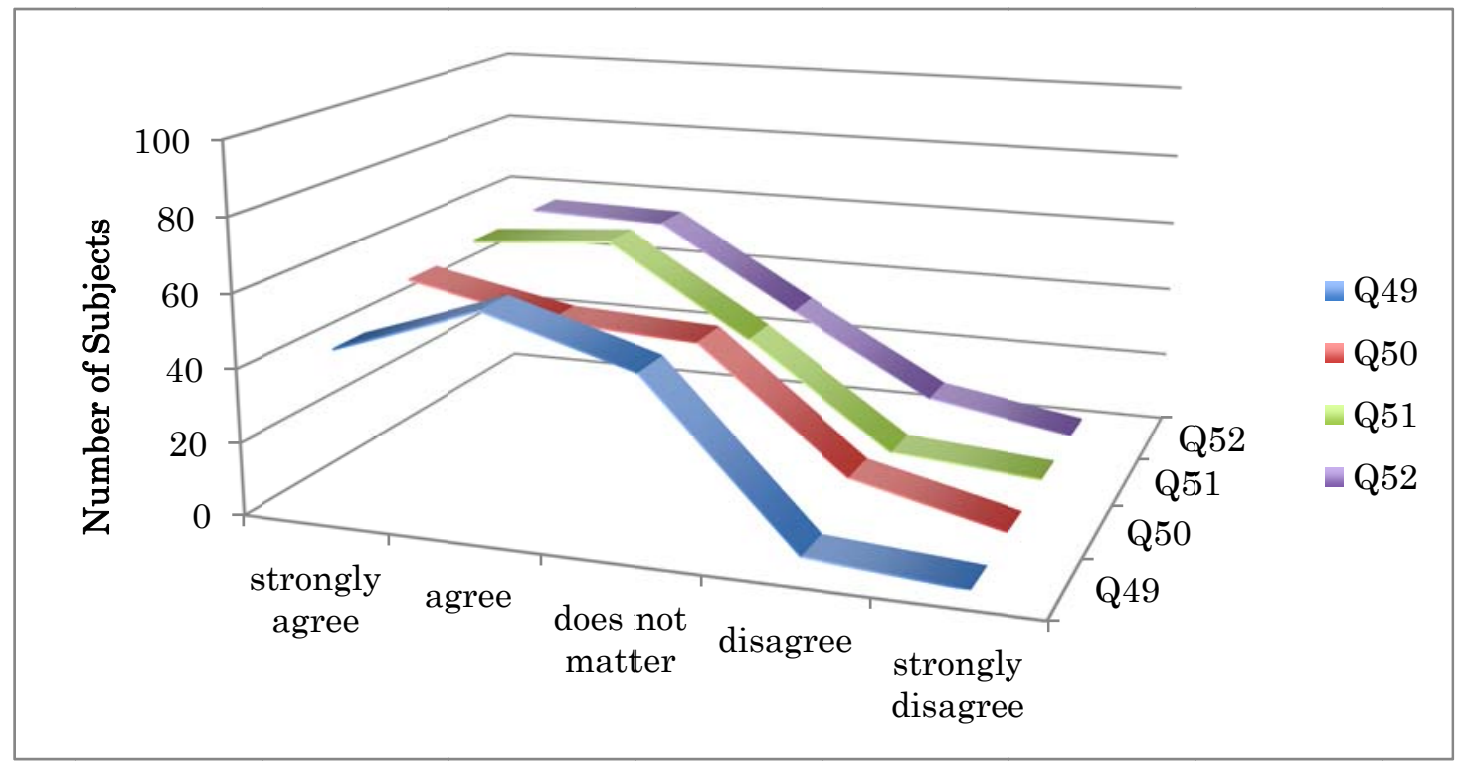

Figure 9. Pronunciation

Subjects from Figure 9 wish to have pronunciation practices every lesson, including accent practice, rhythm practice, and intonation practice. So far, most elementary level Japanese language textbooks seem to show a propensity not to place an emphasis on practicing pronunciation of the language, except textbooks such as the Mizutanis' An Introduction to Modern Japanese (1977) and The JET Programme Japanese Language Course Beginner's Course Book 1 6 (2009), both of which contain various kinds of pronunciation practices just mentioned above. We expect future elementary textbooks to have more pronunciation exercises. 


\subsection{Others}

Survey results for questions from 53 to 67 illustrate that Indonesian learners of Japanese seem to be enthusiastic about learning Japanese; for examples, they want to experience Japanese riddles and games on words, to learn four skills, kanjis, to review exercises, to use authentic materials, and to do pair work, group work, and information gap task. All of these reactions signify that learners in Indonesia are active and positive learners of language.

\section{Free Descriptions}

Part of descriptions about their desired Japanese textbook led us to find out the following. 1) more interesting dialogues and reading, 2) well-balanced fours skills of speaking, listening, reading, and writing, 3) words and phrases being used by Japanese people everyday, 4) column of Japanese pop culture every chapter, 5) ample sentence examples and exercises, 6) introduction of kanji from the beginning, 7) possibility for self-study, 8) reading of kanji in the bottom section of each page, 9) ample illustrations, 10) brief descriptions in Indonesian, 11) application of recent method of language education, 12) more exercises to make sentences. All of these descriptions seem to reflect the reaction to the questionnaires above.

\section{Conclusions}

This research demonstrates that Indonesian learners of Japanese are not very satisfied with the existing Japanese language textbooks. They are looking forward to the emergence of newly written innovative Japanese language textbooks that fit the expectancies of Indonesian learners of Japanese and making the full use of the outcome of contrastive study of language and culture that include various elements that maintain the learners' motivation to learn.

\section{Further Research}

This paper tried to broadly describe what kind of Japanese textbooks are expected to be written in the future for the Indonesian learners of Japanese. However, the participants were limited to university students in Bandung. It is important to launch a full-scale research on the learners from the other areas in Indonesia. A research that presents an ideal picture of Japanese language textbooks that is suitable for the Indonesian learners of Japanese based on a large-scale survey is highly recommended in the future. 


\section{References}

Council of Local Authorities for International Relations(CLAIR)(2009). The JET Programme Japanese Language Course Beginner's Course Book (Vol. 1-6). Tokyo: Bonjinsha Co., Ltd.

Japan Foundation (2011). Survey Report on Japanese language Education abroad 2009. Tokyo: Japan Foundation.

Mizutani, O., \& Mizutani, N. (1977). An Introduction to Modern Japanese. Tokyo: The Japan Times.

\section{Copyright Disclaimer}

Copyright reserved by the author(s).

This article is an open-access article distributed under the terms and conditions of the Creative Commons Attribution license (http://creativecommons.org/licenses/by/3.0/). 